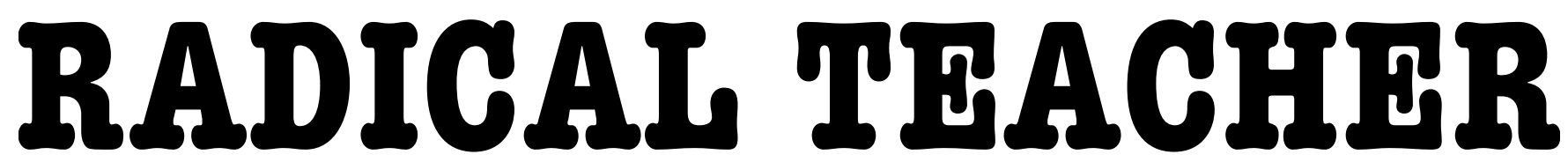

A SOCIALIST, FEMINIST, AND ANTI-RACIST JOURNAL ON THE THEORY AND PRACTICE OF TEACHING

\title{
Teaching Note: Young Adult Literature in the College Classroom: Teaching the Novel Feed
}

\author{
by Jason Myers
}

\begin{abstract}
Whe Spring 2015 semester marked my fourth time teaching ENG 1500: Experiences in Literature at William Paterson University. One of the major objectives stated in the university's description of this course is to help students to develop an appreciation of literature and, since this is a general education course taken by students pursuing various majors and not a class full of English majors, I always take this objective seriously whenever I teach this class. However, given that I have experienced an average of only two to three selfproclaimed avid book readers per section, this has always been an uphill battle. The students are primarily from workingclass backgrounds and many claim to have not even read an entire novel cover to cover in their lives.
\end{abstract} So, how does one teach a group of students not accustomed to reading books to

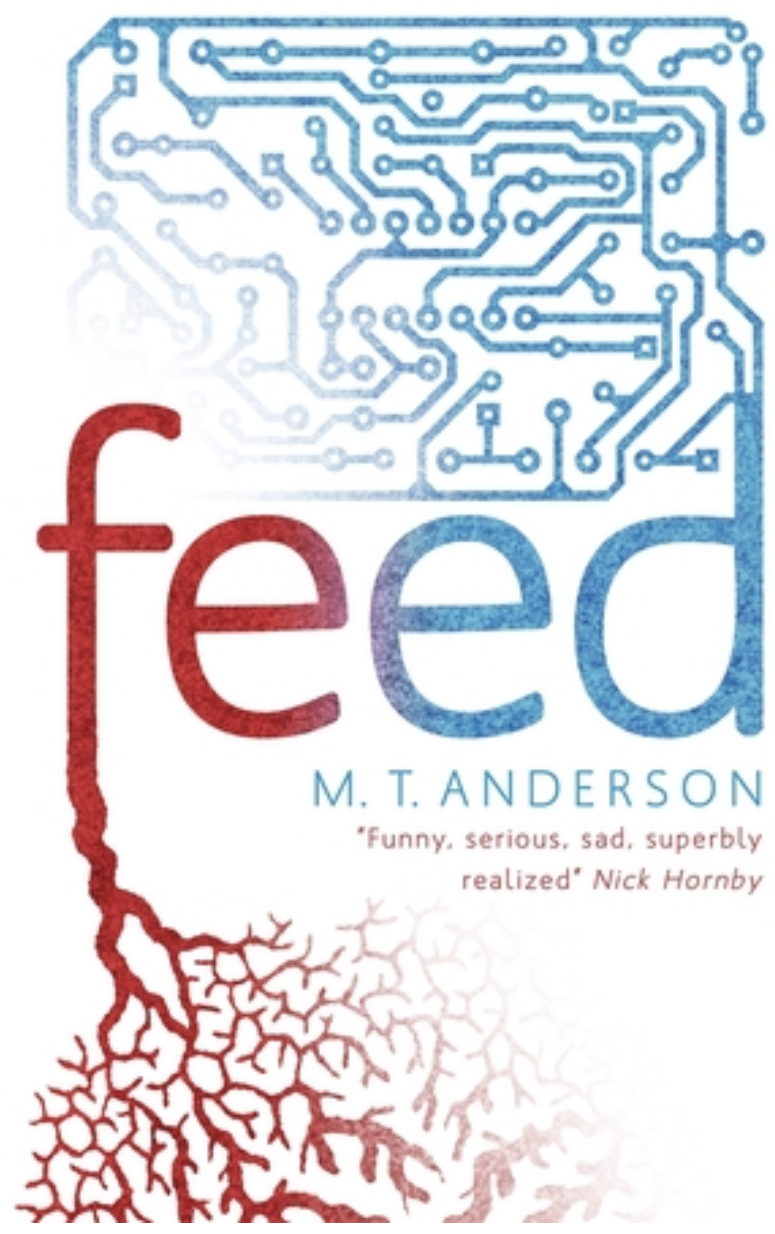

appreciate literature? My answer to this question this semester was to turn to some Young Adult fare. I approach this course not as an introduction to literature, but as the last literature course my students might ever take. I wanted them to enjoy their reading experiences, not simply struggle through difficult reading material, as well as to see the value of seeing the world through the lens of a literary text, even if this text might not be considered "high art." My goal was to present books that I thought the students would find relatable and accessible and then to complicate their readings of these works by teasing out their political content.

One of the books that I chose for the course is a novel entitled Feed by M.T. Anderson (Candlewick Press, 2002), which was a finalist for the National Book Award for Young People's Literature. The novel is a satire that presents a world approximately one hundred years in the future where people are now continuously connected to 
the internet via a chip in their brains called the Feed that most have implanted at birth. As these people grow up, their brains literally form, from cerebral cortex to frontal lobe, around this Feed. Once this process is complete, the brain cannot function without the Feed. The socialization processes the novel's characters undergo are entirely mediated by the Feed, a piece of hardware and an operating system with the main purpose of creating the perfect consumer. The software creates consumer profiles for users based on the advertisements they succumb to, sites they browse, and/or products they purchase, much like how internet advertisers use cookies to mine user data and create tailored advertisements today. The characters are constantly bombarded with advertisements for every occasion, and readers are treated to examples of feedcasts throughout the novel in a quasi-modernist fashion.

On the surface, the Feed itself appears to be a Frankenstein, a future to be feared, but the basic functionality of the Feed and how the characters use it was immediately familiar to my students. While the characters in the novel $\mathrm{M}$-chat each other (through a person-toperson instant messaging system that works like an internet based telepathy) more than they communicate verbally, my students claimed that they text, instant message, snap chat, tweet, etc. more than they sometimes converse with friends face-to-face. In the spirit of this novel, I had my students create their own blogs to reflect on their reading, and the majority of them saw themselves in the young characters, especially relating to the part of the story where they lost access to the Feed after being hacked by a member of a terrorist organization known as the Coalition of Pity at a night club on the moon-out there, I know. Students shared their experiences in writing of the horrors of being somewhere with friends or family and running out of battery life on one or more of their smart devices. It was pretty clear to them early on that the Feed itself was not that much different from the internet today. It merely provided users even more instantaneous access. Many students actually likened it to Google Glass.

On top of this, in a note on the novel at the back of the book, Anderson explains that he is not a Luddite. Once I explained to the class what this meant, they began to question what the novel was really criticizing, and the majority of the class agreed that the target of the satire was not the technology itself but how it has been appropriated and used by its owners: the corporations Feedtech, American Feedware, OnFeed, and Feedlink. To put this in Marxist terms, the issue was not the development of the means of production, even if the product was primarily information, but the relations of production. Most of my students quickly saw that this new technology could be put to better use if it was publicly controlled and used for the betterment of human civilization and not merely to increase profit for monopoly corporations.

The novel's downfall is that it is more focused on exposing and poking fun at consumer culture than investigating the system that engendered it. The relationship between the two main characters Titus and Violet even becomes an extended metaphor for how many Americans consume goods with no care of how or where they were produced and our willingness to quickly discard them when we have lost interest with no real concern as to where these rejected commodities end up. Violet's father, the only academic in the novel, actually accuses Titus of behaving this way after his daughter falls deathly ill as a result of her Feed hardware malfunctioning, and Titus quickly moves on to date another young woman.

\section{The novel's downfall is that it is more focused on exposing and poking fun at consumer culture than investigating the system that engendered it.}

Anderson also positions the only way to resist the Feed as through consumer choice: an action to be undertaken individually and not collectively. The character Violet chooses to fight back by creating a bizarre consumer profile for herself by window shopping for items she knows she will never purchase at the mall. This is equivalent to the argument that consumers have the power to force significant change to a free market system via what they decide to purchase. In other words, Anderson places class struggle at the point of commodity exchange and consumption and not at the point of production itself. Violet's fight is not to raise the working masses to take control of the means of production but to throw a monkey wrench into the system based on the data she feeds it through her consumer choices. However, a few of my students argued that Anderson himself must be aware that Violet's venture is futile because it ultimately ends up leading to her death when Feedtech refuses to fix her malfunctioning Feed device because they view her as an unreliable investment based on her bizarre consumer profile.

That said, a great strength of this novel is its ability to raise students' political consciousness on a variety of different issues. This past semester, I received papers from students who examined how cultural hegemony functions to pacify the characters of the novel even in the face of immediate threat. Due to the devastation of the environment, people in the novel begin to develop lesions on their bodies. These lesions are transformed into fashion statements as soon as the characters of a hit reality television show entitled "Oh? Wow! Thing!" develop them. The President of the United States even puts out a feedcast explaining that the lesions can in no way be the fault of the corporations. The schools in the novel are owned and operated by the corporations and the noun "school" is trademarked throughout the text. Every bit of knowledge is controlled by those in power, and many of my students were able to draw clear connections to popular culture today, their experiences in public schools, and the charter school movement. I even had a couple of students write papers that argued that Violet's upbringing, being that she was from a much less affluent socioeconomic background than that of the other characters and raised by an academic, was the reason that she was able to resist the Feed. The others were blinded by their life circumstances. However, students still struggled a bit with developing 
clear critiques of the state's relationship to the corporations, though this struggle provided us some great opportunities to discuss money in politics and the role of the state with regard to protecting the interests of capital.

\section{. . . a great strength of this novel is its ability to raise students' political consciousness on a variety of different issues.}

I also received some papers that drew connections between the environmental devastation of this speculative landscape and many current environmental issues. In the novel, global warming has rendered the planet unlivable, so people are forced to live under domes both above and underground. They travel in flying cars through a series of tubes. The ocean is dead. They end up laminating whales somehow just so they can place them back into the sea to hunt them. They manufacture their clouds, which are trademarked throughout the text; they produce air via air factories, which they fell trees to build because they are perceived as more efficient; and they grow their meat on meat farms-do not ask me how-because there is no more land for cattle to graze. And all of this has been normalized for the people living in this brave new world. This led several of my students to even take on papers arguing for the need for more environmental activism to prevent a world like this from ever coming into being, a few even linking the state of the environment today to capitalist production and its overconsumption of resources.

The novel alludes to inter-imperialist rivalry when the United States stakes out a claim for the moon against the desires of the Global Alliance, and readers get glimpses throughout the text of an existing third world where people are clearly much more politically active and violently oppressed than they are in the United States. And the form and style of the novel appear to be aimed at raising political consciousness, as well. Feedcasts are interspersed with the first person narrative; the page numbers drop out when the characters are hacked and they lose access to the Feed (as if time stands still); the chapters are short and choppy, like the attention span of the characters; and the novel, though somewhat chaotic throughout, ends on a page with just one sentence written in very small font in the center: "Everything must go." Thus, it forces readers to stop and pay attention to three short words in a way that none of the characters, and most of my students, are used to doing in this fast paced digital world. The words themselves create a double meaning, functioning both as the end of a Feed advertisement for a blowout sale and a political statement. One of my students claimed that she boycotted all social media platforms as a result of reading this novel. While her individual action still falls within the scope of how the character Violet might have read and acted on the novel's final statement above-which is not to say with a greater move towards the understanding that a complete overhaul of the current political and economic system is truly needed to resist the Feed and the unequal profit driven economy it helps to sustain-this student did move from complacency to political action, regardless of how small. And I will take it!

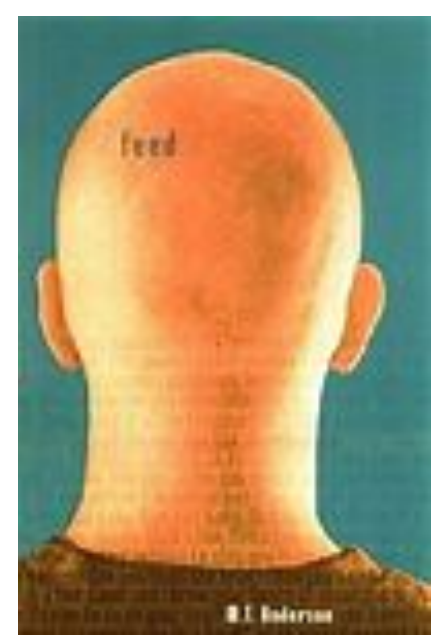

(c) $)$ EY-NC-ND

This work is licensed under a Creative Commons Attribution-Noncommercial-No Derivative Works 3.0 United States License.

UILIS D-Sork

This journal is published by the University Library System of the University of Pittsburgh as part of its D-Scribe Digital Publishing Program, and is cosponsored by the University of Pittsburgh Press. 